Para enlazar con este artículo / To link to this article:

http://dx.doi.org/10.14198/fem.2018.32.12

Para citar este artículo / To cite this article:

Alarcón Zayas, Violeta. «Shameless: una mirada grotesca sobre el amor en el suburbio». En Feminismo/s, 32 (diciembre 2018): 313-341. DOI: 10.14198/fem.2018.32.12

\title{
SHAMELESS: UNA MIRADA GROTESCA SOBRE EL AMOR EN EL SUBURBIO
}

\section{SHAMELESS: A GROTESQUE LOOK ABOVE THE LOVE IN THE SUBURB}

\author{
Violeta ALARCÓN ZAYAS \\ Universidad Complutense \\ violeala@ucm.es \\ orcid.org/0000-0002-1995-5769
}

\section{Resumen}

En el presente artículo se estudiará la representación de los roles de género en las relaciones erótico-afectivas heterosexuales en el contexto social de los suburbios y las clases marginales, en la versión estadounidense de la serie de éxito Shameless. La representación de la serie de los grupos más vulnerables y excluidos pretende evitar representaciones clasistas, pero desde una perspectiva feminista, se indaga si se reflejan o no resistencias y transgresiones en la reproducción de los roles de género, es decir, si en esta ficción hay lugar también para prácticas y discursos contra-hegemónicos en el orden de lo sexual. Para ello se ha desarrollado un análisis que incluye una parte teórica de análisis discursivo del texto audiovisual y otra de investigación cualitativa a partir de entrevistas, para comprobar cómo opera lo grotesco en Shameless desvelando los dispositivos patriarcales del amor romántico y sus contradicciones.

Palabras clave: marginalidad, género, clase, amor romántico, Shameless.

\begin{abstract}
The present article studies how are gender roles in erotic-affective heterosexual relationships represented in the social context of the suburbs and marginal classes, in the U.S.A. version of the successful TV series Shameless. The representation of the series (CC BY 4.0)
\end{abstract}

Feminismo/s 32, diciembre 2018, pp. 313-341 
to the most vulnerable and excluded social groups tries to avoid classist representations, but from a feminist perspective, we investigate if resistance and transgressions are reflected in the gender roles reproduction. That is, if in this fiction there is also a place for anti-hegemonic practices and discourses against the sexual order. In order to do this, we have developed an analysis, which includes a theoretical part, a discursive analysis of audiovisual text, and a qualitative research based on interviews, to see how the grotesque operates in Shameless by revealing patriarchal devices of romantic love and its contradictions.

Keywords: Marginality, gender, seduction, class, romantic love, Shameless.

\section{INTRODUCCIÓN}

La versión de Showtime de Shameless (2011-2018), desarrollada por John Wells, pese a los cambios exigidos por los canales en que se ha emitido, mantiene el espíritu original de Paul Abbot. El creador inglés plasma en ella parte de su propia biografía con la intención de poner en cuestión los estereotipos respecto a lo marginal, haciendo visibles aspectos conflictivos de la cotidianeidad que el imaginario hegemónico obvia, distorsiona o invisibiliza. Por su parte, el realizador Wells mantiene esta perspectiva de crítica a la estigmatización y/o mitificación que se pone en juego al representar las realidades sociales de los suburbios en el imaginario dominante. Wells afirma que la serie refleja desde dentro estas realidades (bien conocidas por Abbot), y subraya que hay una tradición cómica de burlarse de las personas en riesgo de exclusión, pero que en realidad esa gente no «son los otros» (Rochlin AR7). Lo relevante de esta serie, pues, no es el hecho de que retrate lo marginal, sino el modo en que lo hace.

La mayoría de las series mainstream retratan lo marginal de forma extremadamente estereotipada, ridiculizando a los sectores más desfavorecidos de las grandes urbes, que canónicamente podría representar el hogar de Married with children (1987-1997), o bien para exaltar al delincuente juvenil, las bandas callejeras, o el crimen organizado como en Sons of Anarchy (20082014) o Narcos (2015-2018). En contraste con estas representaciones, y pese a conservar muchos de los estereotipos hegemónicos, Shameless marca una nueva forma de reflejar estas realidades, intenta reflejar de forma realista, a veces exageradamente cruda o grotesca, la situación de estos grupos sociales.

Feminismo/s 32, diciembre 2018, pp. 313-341 
Esta perspectiva permite la identificación masiva con esos colectivos que la sociedad desecha como incomprensibles, con los que no se puede hablar ni negociar. La enunciación audiovisual de esta serie logra aproximarnos al suburbio a diferencia del discurso hegemónico que lo silencia y/o caricaturiza, expulsándolo y marginándolo literal (hacia el extrarradio) y simbólicamente (hacia las categorías morales y sociales más bajas y deplorables), a partir, por ejemplo, de mostrar con lupa problemas tan comunes y cotidianos como lo son que se estropee la lavadora, o la dificultad para pagar las facturas, agravados porque quienes los padecen son seis hermanos menores de edad. En esta línea, Shameless retrata en profundidad situaciones clave en la interacción sexual, a menudo situaciones extremas, y permite hacer una crítica a muchos de los dispositivos moralizadores que operan en las series y películas mainstream, pues la crudeza de ciertos conflictos que plantea la serie, pone de relieve los mecanismos sociales y políticos que obligan a estos grupos a mantenerse en la marginalidad social, en especial a las mujeres.

La televisión, como cualquier texto, supone un contexto de recepción que suscita diferentes procesos retóricos; de entre ellos, centraremos especialmente nuestra atención en la identificación que:

implica no sólo una correspondencia biunívoca entre un televidente y cierto personaje favorito, sino también una identificación más general, que se da en diferentes niveles, entre lo que aparece en la pantalla y la vida, las opiniones de quienes están frente a ella. [...] Apenas podemos imaginar un texto de televisión que produzca algún efecto sin esa identificación. (Morley 303)

Así que desde esta mirada peculiar al detalle que observamos en Shameless, una mirada desde «abajo», analizaremos la representación y la identificación con los modelos de amor y deseo heterosexual que observaremos a través de las relaciones sexo-afectivas de la protagonista femenina principal.

\section{MARCO TEÓRICO Y ESTADO DE LA CUESTIÓN}

\subsection{Relaciones sexo-afectivas: ¿hay amor más allá del amor romántico?}

Cuando hablamos de «amor romántico» aludimos al término empleado por el feminismo para definir el ideal de amor hegemónico patriarcal, término que recoge y desarrolla Mari Luz Esteban como un tipo de relación que 
tiende aquí y ahora a enfatizar el amor por delante de otras facetas humanas y subrayar el amor pasión frente al resto; que incita a la búsqueda de la trascendencia, incluso de la felicidad, a través del amor, y se convierte así en la modernidad en un sustituto de la religión; que vincula la pasión a la tragedia y la muerte, y otorga el máximo valor a cualquier proceso amoroso que implique superar dificultades; que idealiza la relación e hipertrofia la parafernalia amorosa. (Esteban 44)

Este tipo de amor se caracteriza por ser una relación heterosexual (aunque se traspone a relaciones de otro tipo), pasional, monógama, que se concibe como fusión o entrega total al otro/ a la otra, como refugio de los males del mundo, pero también como sacrificio. Esta forma de amor, la pedominante en el imaginario hegemónico y mass-mediático, se convierte en la forma privilegiada, incluso única y verdadera forma de amar.

La romántica es una relación fuertemente ritualizada, cuyo esquema, roles y valores se reiteran una y otra vez en los relatos y ficciones de los mass media, desde la contradicción de la idea de un amor desinteresado y libre, pero en el que los rituales enmarcados por el capitalismo se le exigen al romance (las citas, los viajes, los regalos, etc.), supone una relación totalmente dependiente de lo económico:

el éxito de los encuentros románticos (es decir, su capacidad de alejar a la pareja de las rutinas cotidianas) depende en gran medida del grado de ritualización y liminalidad, pero en la cultura posmoderna, [...] esa ritualización se logra con ayuda de la mercancía. (Illouz 371)

Pero por otra parte, los relatos culturales mediáticos que construyen y codifican el amor romántico, lo presentan como un amor verdadero y subversivo del mundo materialista, un amor incondicional y desinteresado:

El amor romántico no es racional sino irracional, no es lucrativo sino gratuito, no es utilitario sino orgánico, y no es público sino privado. En síntesis, el amor romántico parece evadir las categorías tradicionales según las cuales se concibe el capitalismo. Tanto en el ámbito académico como en la cultura popular y en la esfera del «sentido común», el amor romántico se eleva por encima del intercambio comercial e incluso más allá del orden social en general. (Illouz 19)

Pero a la vez, es un mundo lujoso, donde se posee tiempo indefinido para el placer, apartado de la rutina y a salvo de las vicisitudes económicas: «Las 
situaciones románticas son exóticas (como las islas de Hawai), divertidas (como un viaje o una fiesta), costosas (como un pasaje de avión o un traje elegante), mágicas (como el «encanto») y relajadas» (Illouz 169).

En Shameless este ideal amoroso funciona de fondo enmarcando los deseos y aspiraciones de los personajes, pero al producirse en el contexto del suburbio y de las clases sociales marginales, las contradicciones del amor romántico cobran dimensiones grotescas.

\subsection{Una mirada grotesca al suburbio}

El modo de visión que hemos detectado que prevalece en esta serie, la comicidad que todas las personas entrevistadas calificaron de «humor negro», se basa en una forma de mirar que invierte el idealismo y que no supone la mera sátira exterior de personajes o situaciones concretas. Pese al elemento «satánico», inherente según Baudelaire a la risa, a lo cómico, por el que observamos desde la altura la desgracia ajena, detectamos aquí lo que Bajtin denomina «realismo grotesco» en su obra La cultura popular en la Edad Media y en el Renacimiento, una estética, una cosmovisión y un humor herederos de la fiesta carnavalesca popular. Esta es una perspectiva en la que el pícaro, el delincuente, la prostituta y el bufón toman la palabra y se igualan al rey, al empresario, al médico y a la monja. Un humor que habla de la risa universal donde se borran las jerarquías. Una risa que no solo nos provocan los demás, sino nosotros mismos, lo cual acorta las distancias con esa alteridad que se establece desde la hegemonía respecto a las realidades sociales marginales del suburbio.

Este humor universalizador, donde todos reímos y somos susceptibles de ser objeto de risa, nos acerca de una forma horizontal a las realidades marginales, aunque de un modo realista, duro, irónico y a la vez tierno, pero no sentimental. Usaremos el término de «realismo grotesco» o «grotesco carnavalesco» como revalorización de la cosmovisión festiva popular, del cuerpo, sus placeres y sus necesidades. Otras veces nos referiremos a lo «grotesco romántico» (Kayser 84), producido por la extrañeza ante lo cotidiano distorsionado y distanciado cuando se unen dimensiones que no asociamos juntas, adquiriendo el humor un tono lúgubre y perdiéndose la ambivalencia.

Feminismo/s 32, diciembre 2018, pp. 313-341 
Desde la modernidad lo grotesco funciona para dar voz y protagonismo a aquellos quienes desde el imaginario hegemónico son invisibilizados, ridiculizados y oprimidos. Esto conecta como veremos con la teoría de género, pues lo femenino es aquello que se opone a lo masculino como hegemónico, los atributos asociados a lo femenino aparecen a menudo asociados a lo grotesco; cuando lo femenino desborda los márgenes que se le han impuesto dentro de la dicotomía esencialista, se muestra como aberrante e incluso monstruoso (Connelly 2015).

Lo llamativo de esta serie, razón por la que la elegimos, no es sólo la proximidad hacia unos personajes bien construidos desde una intimidad que otras series no permiten, sino que este realismo se asocia a la «gracia» que hacen, a la risa que provocan, desde la perspectiva desidealizadora.

Aquí nos centramos en el poder subversivo y desenmascarador de la risa que provoca lo grotesco, un humor que no se basa en hacer mofa de otras personas, en la mera sátira de otro particular, sino en la extrañeza e hilaridad que nos produce la realidad. Este tipo de humor, que incita más a pensar que a reír, será el que analizaremos en la serie.

\subsection{Un estudio de género}

Analizaremos la representación de unas realidades sociales estigmatizadas, subordinadas, atravesadas por diferentes factores de subordinación como los de la clase, la raza o el género. Es decir, conceptos como mujer, marginado, o loco, se basan siempre en sistemas binarios de exclusión, fuerte/débil, normal/ anormal, rico/pobre, sano/enfermo. Estos sistemas se fundamentan en una ficción social que presupone sujetos, que desempeñan una serie de roles naturalizados para ser reconocidos por la ley como tales sujetos, es decir, ser mujer $\mathrm{u}$ hombre se define por unas acciones determinadas:

En este sentido, género no es un sustantivo, ni tampoco es una serie de atributos vagos, porque hemos visto que el efecto sustantivo del género se produce performativamente y es impuesto por las prácticas reglamentadoras de la coherencia de género (Butler, El género en disputa 84).

Nos enfrentaremos por tanto a Shameless desde una perspectiva no sólo de género sino interseccional, para estudiar la representación que se hace 
de los roles de género en las interacciones sexo-afectivas en un contexto heterosexual:

Feminism also provides a way of looking at the world, a lens through which to consider how power circulates around the axis of not just gender, but sexuality race, and class. Feminism is an analytical system that gives us tools for seeing ourselves in relation to one another. (Dolan 1)

Determinaremos qué conceptos de feminidad y masculinidad laten consciente e inconscientemente en la serie de Shameless, y cómo se desarrollan en entornos que se consideran marginales, y por tanto fuera de lo normativo. «Lo grotesco aparece al romper con los límites culturales, comprometiendo y contradiciendo lo que es "conocido", "propio" o "normal"» (Connelly 25). Lo grotesco, por tanto, es cómplice de la mirada feminista en el sentido de que muestra las relaciones de opresión desde la perspectiva de los/las oprimidos/ as, poniendo en tela de juicio la naturalización de dichas relaciones.

\section{OBJETIVOS DE LA INVESTIGACIÓN}

1. Comprobar si la mirada grotesca trata las relaciones erótico-afectivas de una forma alternativa o reproduce los ideales del amor romántico y los roles de género tal cual se conciben desde la normatividad hetero-patriarcal.

2. Rastrear la recepción de estas representaciones, la percepción de estos constructos que propone la serie, y los grados de identificación/distanciamiento por parte de un público joven, de diversas clases sociales y género.

\section{METODOLOGÍA}

Para abordar este trabajo combinamos el análisis discursivo del texto audiovisual con la investigación sociológica a través de una metodología cualitativa basada en entrevistas, sin ser éste un estudio estrictamente de recepción. Es decir, contrastamos el discurso de la serie con los recogidos en las entrevistas. Primero, se realizó un análisis estrictamente semiótico de 4 secuencias significativas de la primera y tercera temporadas de Shameless. En segundo lugar, se realizaron 5 entrevistas a 8 personas de ambos sexos ( 5 mujeres, y 3 varones) de edades comprendidas entre los 21 y los 38 años. La selección de

Feminismo/s 32, diciembre 2018, pp. 313-341 
los informantes se basó en que hubieran visto las seis primeras temporadas, y que fueran de distinto sexo y clase social, para comprobar si estas diferencias influían en su percepción e identificación y cómo. Por último, para llegar a unas conclusiones generales contrastamos los resultados de ambas fases.

\begin{tabular}{|c|c|c|c|c|}
\hline Temporada & Capitulo & Minutos & Descripción secuencia & Preguntas \\
\hline Temporada 1 & Capitulo 1 & $752^{\prime \prime}$ & $\begin{array}{l}\text { Dormitorio de los hermanos Gallagher, } \\
\text { Fiona se prepara para salir. }\end{array}$ & \multirow{4}{*}{$\begin{array}{l}\text { ¿Quién le parece ella protagonista de esta serie? ¿Por } \\
\text { qué? } \\
\text { ¿Se identifica con algún personale de la serie? ¿Con } \\
\text { quién? ¿Por qué? } \\
\text { ¿Qué le parece el personaje de Fiona? ¿Qué quiere, } \\
\text { qué busca? ¿Y Jimmin? } \\
\text { ¿Qué tipo de relación cree que establecen Fiona y } \\
\text { Jimmy? ¿Qué papel cree que tienen cada uno en la } \\
\text { relación? } \\
\text { ¿Qué piensa sobre las relaciones sexo-afectivas que } \\
\text { establece Fiona a lo largo de las seis primeras } \\
\text { temporadas? }\end{array}$} \\
\hline Temporada 1 & Capitulo 1 & $854^{\prime \prime}$ & $\begin{array}{l}\text { Discoteca donde se produce el cortejo de } \\
\text { Jimmy a Fiona. }\end{array}$ & \\
\hline Temporada 1 & Capitulo 1 & $15^{\prime} 57^{\prime \prime}$ & $\begin{array}{l}\text { Escena de seducción entre Fiona y Jimmy } \\
\text { en la cocina de los Gallagher. }\end{array}$ & \\
\hline Temporada 3 & Capitulo 5 & 3957 & $\begin{array}{l}\text { Escena en el jardin ce los Gallagher donde } \\
\text { Jimmy y Fiona disculen. }\end{array}$ & \\
\hline
\end{tabular}

Primeramente, analizamos el punto de vista desde el que se construye la enunciación y qué tipo de mirada predomina. La investigación cualitativa se desarrolló a través de dos tipos de entrevistas tras la proyección de las escenas seleccionadas. Por un lado, mediante 2 entrevistas triangulares, técnica que supone una opción intermedia entre las entrevistas personales y los grupos de discusión. Consiste en la confrontación de dos personas entrevistadas más un moderador con un papel orientador y poco directivo. Así mismo realizamos 3 entrevistas en profundidad, consistentes en una conversación estructurada con informantes clave, a través de una guía de entrevista, consistente en preguntas abiertas o temas a tratar derivados de los indicadores que desean explorarse (Rojas Soriano 217). En las entrevistas hemos recogido cómo se despliegan los procesos de identificación y qué estereotipos y campos semánticos se desarrollan en el discurso de las personas entrevistadas respecto a los temas propuestos.

La última etapa de la investigación consistió en contrastar los resultados del análisis discursivo con los datos ofrecidos por los espectadores, a partir de su percepción. Tratamos así de buscar confluencias y discordancias entre las ideas analizadas previamente con las de las personas entrevistadas, para validar o refutar el análisis del discurso. 


\section{FIONA: EL AMOR ROMÁNTICO Y LAS CENICIENTAS DEL SUBURBIO}

\subsection{El amor romántico cuando Cenicienta es madre}

Nos encontramos ante un hogar disfuncional en un barrio marginal de Illinois en el que seis hermanos menores de edad deben sobrevivir por sí mismos pues el padre es un alcohólico politoxicómano totalmente irresponsable, y la madre bipolar los ha abandonado para fugarse con una amante. Fiona (Emmy Rossum) es la mayor de los Gallagher. Sustituye a la madre ausente, a quien los hijos repudian por su promiscuidad, lo cual consideran la causa principal por la que es mala madre. La maldición de la herencia familiar, interpretada como fatalidad, hará que Fiona sea siempre sospechosa de encarnar la maldición materna. No obstante, ella ha cumplido el papel que su madre jamás desempeñó. Desde niña se ha encargado de trabajar dentro y fuera de la casa, y de cuidar a su padre y hermanos: evitar que Servicios Sociales los separe, intentar que estudien, que no se metan en problemas y que salgan adelante. Ella misma se impone esta tarea de cuidados, y el resto asume su rol como natural. El motor principal del personaje de Fiona al principio de la serie es ser «querida y necesitada», como ella admite explícitamente en varias ocasiones, por otro lado, en sus relaciones amorosas busca protección, ser rescatada y cuidada.

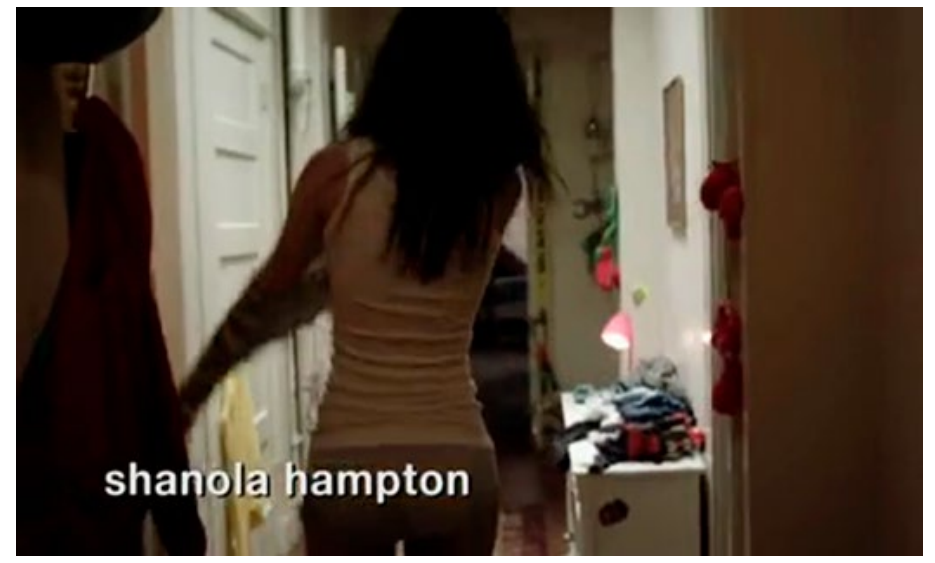

Feminismo/s 32, diciembre 2018, pp. 313-341 


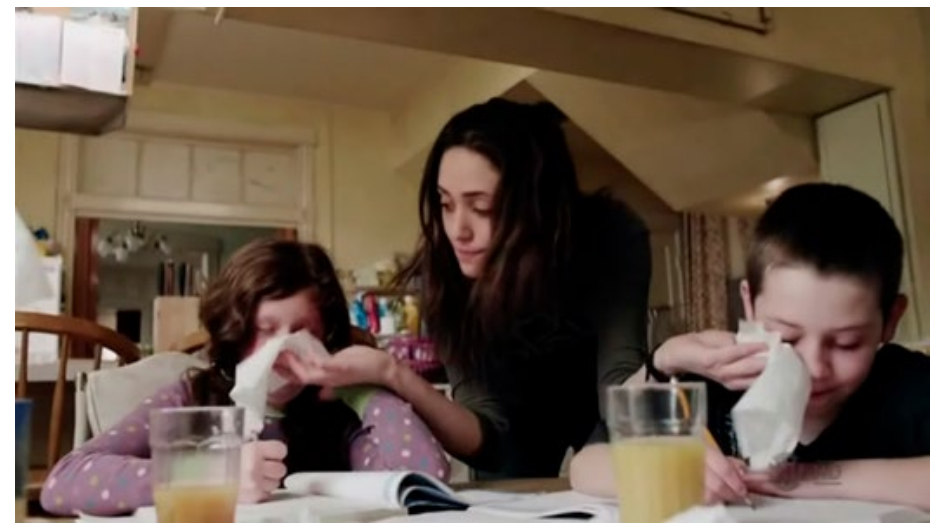

Este personaje es percibido por el $40 \%$ de las personas entrevistadas como la protagonista de la serie y es además con quien más se identifican todas las mujeres que han participado en las entrevistas. Por ejemplo: «Yo me identifico con Fiona, en... la dificultad que tienes, según tus circunstancias, para salir adelante, o como las cosas de tu día a día que te parecen normales cuando sales fuera resultan muy problemáticas y no se comprenden, o cuando te esfuerzas mucho para que algo salga perfecto y luego te falta un recurso y no lo consigues o no te lo valoran», expresa una mujer de 31 años de clase media.

Los varones la consideran «guapa y aburrida», las mujeres se identifican con las dificultades con las que se enfrenta y con los roles que adopta tanto en el hogar como en sus relaciones amorosas, ambos roles percibidos como estereotípicos. Pero ¿realmente representa los estereotipos hegemónicos de mujer?, ¿o representa más bien el esfuerzo frustrado de encarnar ambos estereotipos en los que el resto de mujeres somos impelidas a vernos reflejadas y a tratar de alcanzar?

Ahondemos un poco más en el personaje. Lo que caracteriza a Fiona y a sus hermanos es saber sacar el máximo partido de lo que tienen para sobrevivir: son luchadores, rebeldes y con carácter, debido a su situación social. Pero Fiona se diferencia del resto porque se ha sacrificado por completo por su familia, abandonó sus estudios y trabaja en cualquier cosa, convirtiéndose en madre soltera, lo que supone desempeñar el rol tradicional femenino de cuidados más el masculino de manutención. Fiona es por tanto una joven fuerte, orgullosa y decidida que quiere salir y sacar a sus hermanos de la

Feminismo/s 32, diciembre 2018, pp. 313-341 
miseria por sí misma. Intenta ascender por sus propios medios, sin embargo, encuentra muchas dificultades, y aunque se resiste a dejarse ayudar y no quiere ser una mantenida, sus circunstancias económicas la hacen aceptar ayudas y favores, sobre todo económicos y principalmente de varones, aunque también de mujeres, que se sienten atraídos/as sexualmente por ella. Es hábil en el juego de la seducción y el deseo, y si lo considera necesario, se aprovecha de su belleza y juventud para obtener beneficios de los hombres que están en situación de poder respecto a ella, por ejemplo, con los agentes de policía en las habituales detenciones de miembros de su familia, pero también para lograr ascensos, trabajos, o retrasar el pago de recibos, etc. Pero cuando alguien trata de abusar de ella, se defiende, e incluso chantajea a uno de sus jefes que la acosa en el trabajo.

Aunque habitualmente no se amolda a los rituales estéticos femeninos: casi nunca se maquilla, ni usa sostén ni tacones, etc., se hace mucho hincapié, a lo largo de toda la serie, en su atractivo físico, tanto explícitamente por las miradas y comentarios del resto de actantes, como tácitamente por su vestuario, que resalta su estilizada figura con ropa muy ajustada. Además, la mirada que se ejerce sobre su cuerpo la hipersexualiza, no hay capítulo en el que los recurrentes travellings no encuadren su trasero en ropa interior con minúsculas minifaldas o con jeans ajustadísimos meneándose mientras organiza la casa, sirve mesas, o prepara el desayuno a sus hermanos. Fiona siempre se coloca ante el espectador como objeto de deseo, queriéndolo ella o no: cuando baila en una discoteca o cuando friega los platos, no puede escapar al juego del deseo, a la mirada a la que somete la cámara su cuerpo como objeto y a la que obliga al espectador (figs. 3a, 3b, 4. ${ }^{a}$ y $4 b$ ). Como expresa Mulvey, cuando la mujer se nos expone directamente sin mediación, desde una mirada erótica, masculina y heterosexual

la poderosa mirada del varón protagonista (característica del cine narrativo tradicional) se quiebra en favor de la imagen que está en compenetración erótica directa con el espectador. La belleza de la mujer como objeto y el espacio en la pantalla se funden; ella deja de ser la portadora de la culpa y pasa a ser un fruto perfecto, cuyo cuerpo, estilizado y fragmentado por los primeros planos, es el contenido de la película y el receptor directo de la mirada del espectador. (Mulvey 373)

Feminismo/s 32, diciembre 2018, pp. 313-341 

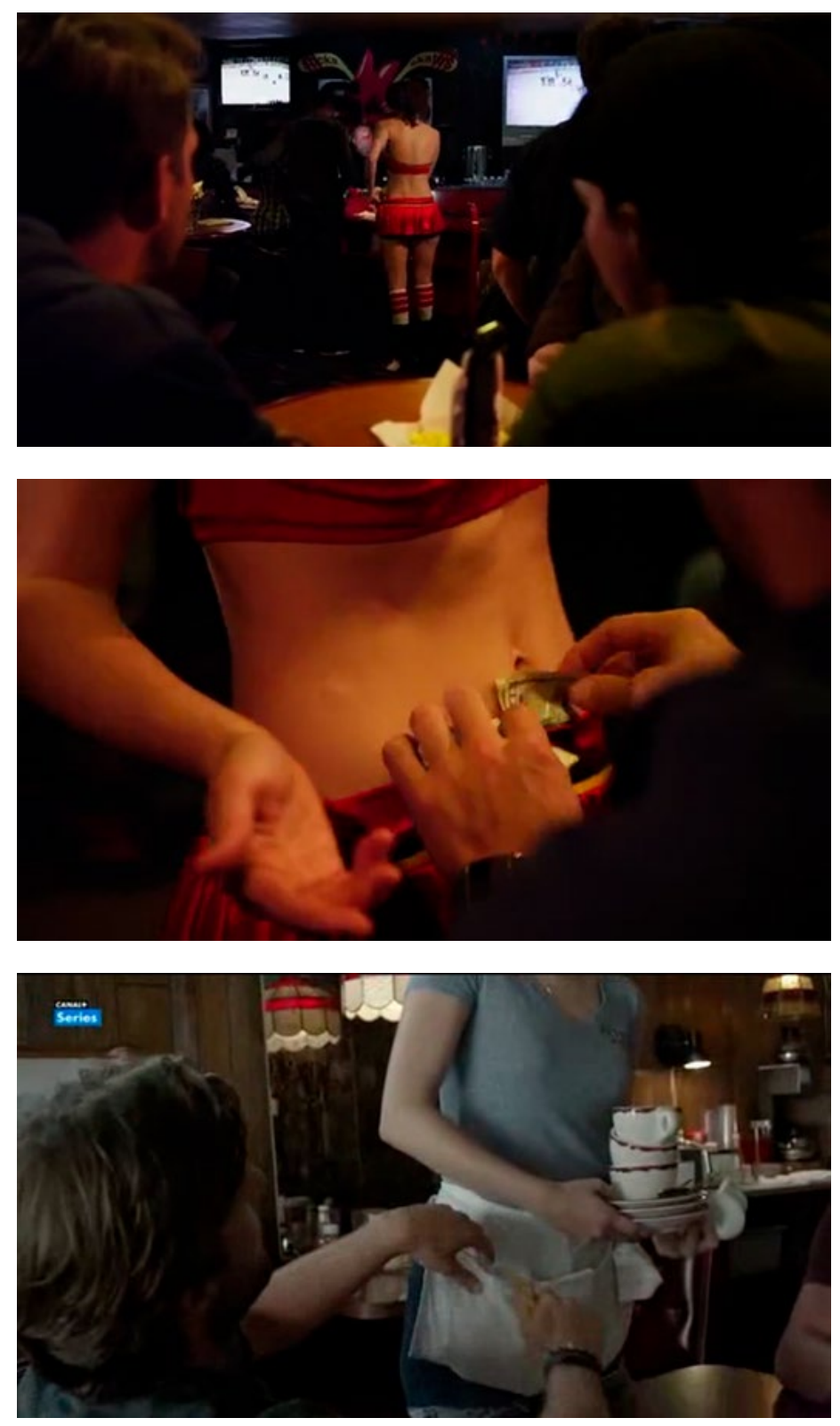

Feminismo/s 32, diciembre 2018, pp. 313-341 


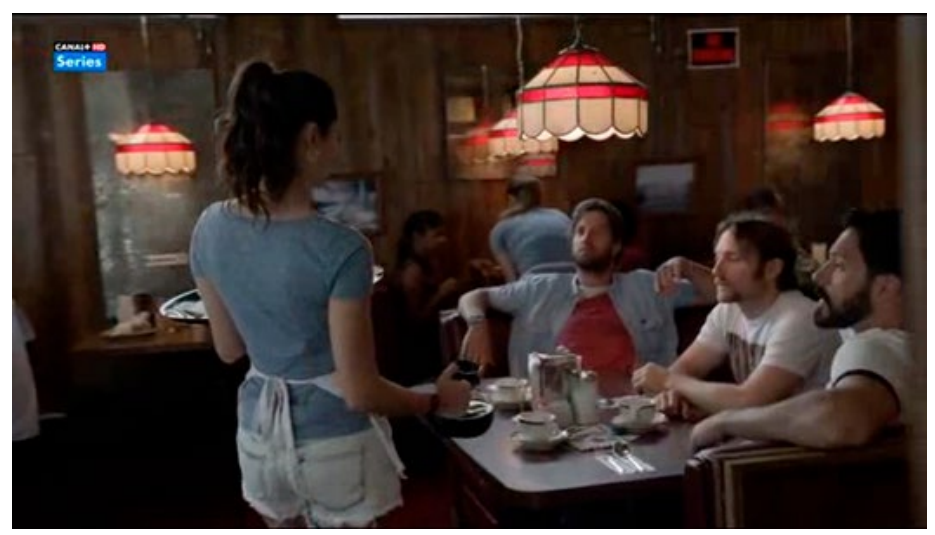

Otra forma de aludir a su atractivo físico es que el resto de personajes, sobre todo su familia y parejas, le recriminan su promiscuidad. A pesar de no ser el personaje que más flirtea, ni quien más relaciones sexuales tiene, el modo impulsivo y pasional en que interacciona amorosa y sexualmente parece contradecir y poner en peligro el papel de tutora de sus hermanos y cabeza del hogar, que aunque auto-impuesto, paulatinamente todos le atribuyen como su rol natural.

En Fiona, como en sus hermanos, encontramos una lucha constante entre lo que son y lo que desean ser, ella se debate entre su anhelo de estabilidad y seguridad, que identifica con el ascenso social, y su lado Gallagher, su carga «familiar» como ella dice, o en términos de Bourdieu, su habitus, el del suburbio, que le lleva a sentirse atraída por lo que ha conocido: el peligro, la delincuencia, las drogas, las situaciones límite y las emociones fuertes (23). En su caso, por ser mujer, oscila entre los papeles estereotípicos femeninos: dedicarse a los cuidados, a los otros («madre», «esposa»), o buscar su propio placer («puta», «golfa»). La segunda opción es la que prevalece en su «estirpe», de lo que son prueba su madre o su abuela, y este «gen de puta» es el que los otros personajes perciben como motivo principal de sus fracasos amorosos. No obstante, las relaciones erótico-afectivas de Fiona son comprendidas de otra forma por las mujeres entrevistadas: «En las relaciones de Fiona sí que veo mucho el estereotipo de la relación de amor en la que la mujer depende del hombre y siempre es ella quien corre el riesgo y no él, él siempre tiene 
el control, yo me identifico con ella en el rol que asume», aprecia una mujer de clase media, de 26 años. Según esta informante, Fiona cumple el rol femenino de la pareja tradicional: se somete y se sacrifica (»corre el riesgo»). Es más vulnerable, por eso se identifica con ella, con sus errores y sus fracasos. Pero por el mismo motivo, otras se distancian: «Con Fiona donde desesperas es en lo romántico, en la casa la entiendes, porque es muy complicado, pero en lo romántico dices: ¡Date cuenta!, y repite y repite siempre lo mismo, y todo le sale mal». Afirma una mujer de 23 años, de clase obrera, que observa de forma muy crítica el romanticismo amoroso en la serie y se identifica más con el rol de cuidados.

\subsection{La seducción como mascarada}

Las relaciones sexo-afectivas de Fiona se verán siempre atravesadas por sus contradicciones: ser fuerte/protegida, buscar peligro/seguridad, ser independiente/ necesitada, cuidar/ ser salvada. Por su papel de madre, al principio de la serie rechaza el romanticismo para ser una mujer autónoma, y se resiste a enamorarse y comprometerse. Vamos a analizar la relación con Jimmy (Justin Chatwin), su primera pareja, quien cambiará su perspectiva, pues tras él comenzará una búsqueda incesante e infructuosa de una figura masculina que le garantice protección y estabilidad (que no recibió de sus padres) y que a la vez sea fuente de emociones fuertes y diversión (a las que está habituada).

Jimmy, en principio, parece el chico perfecto para Fiona, «su príncipe azul», pues satisface ambas tendencias que pugnan en ella: la protección y la pasión. Vero (Shanola Hampton), la mejor amiga de Fiona, lo describe como un chico "guapito de cara», lo que se suma al atractivo del delincuente bohemio, pues el carácter peligroso e ilegal del lucrativo «trabajo» de Jimmy, que es robar coches de lujo, atrae irresistiblemente a Fiona. Por otro lado, para conquistarla, pues ella se niega a tener una pareja, además del discurso amoroso de libreto y los caprichos románticos que propicia el dinero, intenta proporcionarle estabilidad: paga facturas, le regala una lavadora, un coche, y cuida de sus hermanos, los lleva al colegio, etc. Pero Jimmy no es lo que parece: oculta su verdadero nombre, y que es un estudiante de medicina adinerado jugando a ser un delincuente que quiere «salvar» a Fiona de su rol de Cenicienta.

Feminismo/s 32, diciembre 2018, pp. 313-341 
Fiona y Jimmy se conocen en el primer capítulo de la serie. En el minuto 7'52» encontramos a Fiona-Cenicienta luciendo un vestido azul de fiesta que no puede permitirse, por lo que lo compra para ir a la discoteca y al día siguiente devolverlo. Se trata de una escena cómica y caótica en la que se muestran las carencias del hogar, pero también la solidaridad con la que lo afrontan: ante la pobreza, todos los hermanos comparten lo que tienen, tanto la ropa como los productos de aseo. Así, mientras Fiona le pide desodorante a su hermano Lip (Jeremy Allen White) con una toalla en la cabeza y cepillándose los dientes, su cómplice o «hada madrina», Vero, le quita la etiqueta del vestido con un etiquetador que robó de una tienda.

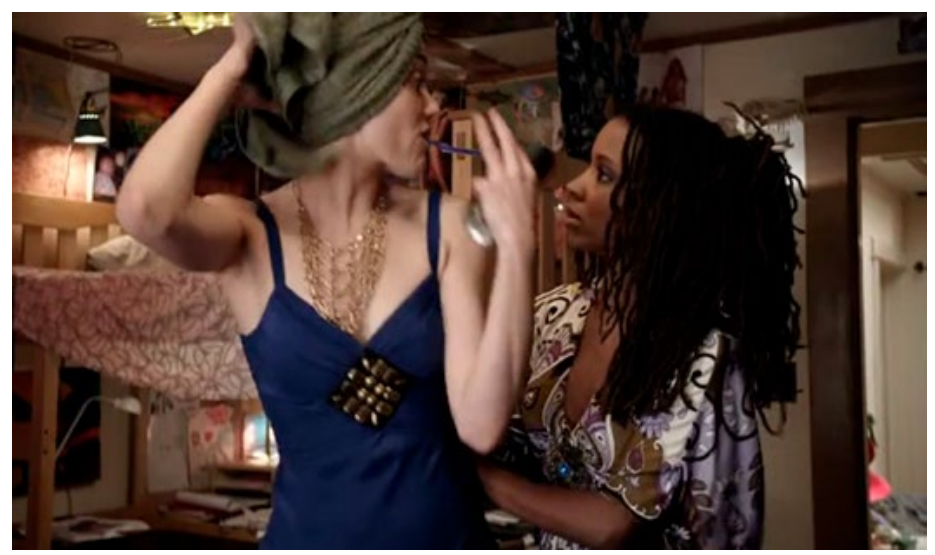

A continuación, en el minuto 8'54», Fiona y Vero se encuentran en una discoteca. Fiona baila y el foco de luz cae sobre ella. Destaca además del resto porque se mueve muy rápido, arrítmica, agitando la cabeza sensual y alocadamente. En realidad, la vemos como la está observando Jimmy, que acecha desde lo alto de una grada de la discoteca, apoyado en la barandilla bebiendo cerveza. Fiona no se da cuenta. Baila, se toca el pelo insistentemente, ríe, sacude los brazos y mece las caderas. Jimmy no le quita el ojo de encima y sonríe: ya la ha elegido, como luego le explicitará él, afirmando su papel activo en el cortejo. Esta idea se refuerza en el estribillo de la canción My first kiss, del grupo de electrónica $3 .{ }^{\circ} \mathrm{H} ! 3$, de contenido explícitamente sexual, donde se 
afirma que con la primera caricia el hombre hace suya a la mujer «que nunca tendrá suficiente» si el hombre «a su manera» la hace gozar.

La canción deja claro que el primer encuentro será crucial, que él la controlará con el sexo. De hecho, que él se encuentre solo, relajado, observando y calculando como un cazador, desde una posición privilegiada (desde lo alto) que le permite observar sin ser visto, mientras ella baila, se exhibe, provoca esperando a que alguien la corteje, reproduce fielmente los roles del galanteo heterosexual. Él disfruta de la visión del cuerpo de ella, convirtiendo a los espectadores en voyeurs y cómplices de su fascinación.
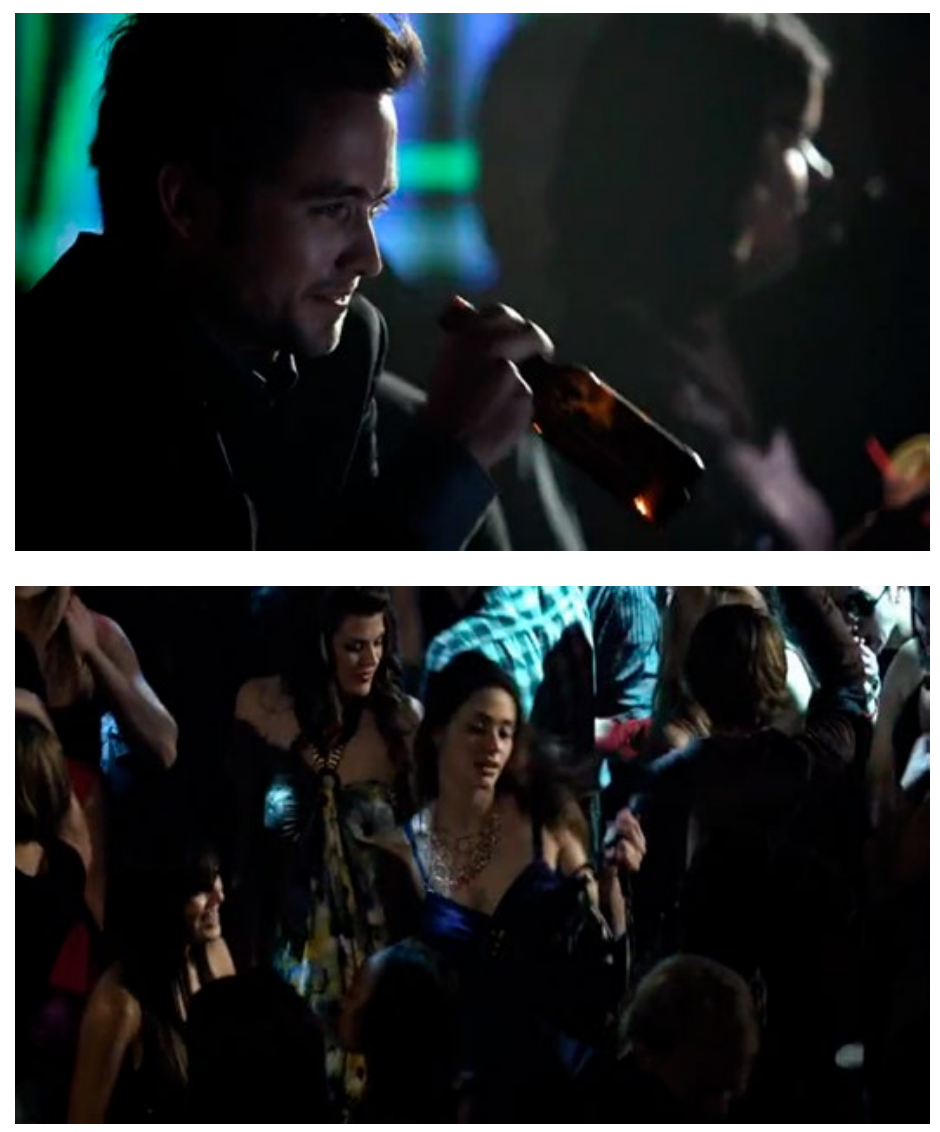

Feminismo/s 32, diciembre 2018, pp. 313-341 
Acaba el estribillo de la canción y la cámara se desliza hacia la izquierda y sigue a un hombre, alto y musculoso que avanza decidido a través de la multitud hacia Fiona. Ella le sonríe y se contonea contra él. Jimmy mira atento, tenso ante el rival. De pronto el chico tira del bolso y sale corriendo. Fiona empieza a gritar y le persigue junto a Vero. Jimmy aprovecha la oportunidad y sale corriendo detrás del ladrón, pero el héroe en su carrera, en la que casi parece que vuela, se choca (y lo vemos a cámara lenta para acentuar lo irrisorio) con una camarera que llevaba una bandeja llena de copas, cayendo ambos, estrepitosamente, al suelo. Finalmente, en la calle el ladrón escapa en una furgoneta que le esperaba fuera, mientras Vero y Fiona le gritan. Jimmy llega cuando ya se ha ido. Ellas se presentan y, como han visto su lance, del que ha salido empapado y magullado, se lo agradecen y quieren volver a entrar a la discoteca con él, pero el enorme guarda de seguridad les impide la entrada. Ellas toman la iniciativa, le insultan y van a buscar un taxi, pero Jimmy, que no es muy alto ni fornido, juega astutamente con el factor sorpresa, y de un puñetazo tumba al gigante, para salir inmediatamente corriendo detrás de ellas, cruzando la calle temerariamente mientras los coches circulan y casi lo atropellan, pero dejando así atrás al enfurecido guarda. Desde la otra acera, los tres se ríen y hacen mofa de él, reforzando vínculos a través de la burla. Luego, tras haber restituido, aunque paródicamente, la honra de la damisela en apuros, remata el ritual llevándola a su casa en coche, símbolo del poder masculino y clave en el relato hegemónico del galanteo.

Ella se ha disfrazado, se ha «feminizado» para ser deseada como lo ha de ser una mujer dentro del ideario hegemónico erótico: y así las mujeres «[...] con su actitud pasiva, intentan obtener, suscitando el deseo, la conjunción a la que los hombres llegan persiguiéndolas. Ellas no son más deseables que ellos, pero ellas se proponen al deseo» (Bataille 137). Desde una perspectiva heterosexual basado en un binarismo esencialista de los géneros, la mujer se propone «como objeto al deseo agresivo de los hombres» (Bataille 137), no de las mujeres, y el papel de sujeto, de acción y de pasión es el masculino, hacia lo femenino. La mascarada en la seducción funciona así, mediante el artificio se finge, se expone el cuerpo femenino, preparado para la situación especial, y así se exageran los roles de género (él observa, espera, interviene), ella sólo se acicala y se expone. De esta forma se produce una mímesis cómica del ideal amoroso heterosexual:

Feminismo/s 32, diciembre 2018, pp. 313-341 
Se trata de un proceso absolutamente ritualizado a lo largo de toda la vida, (...) sobre todo en la infancia y juventud, además de todo tipo de prácticas de interacción social y anticipación (conversaciones, bailes, fiestas, citas, sms...). Rituales sociales, en definitiva, donde se enfatiza la heterosexualidad y donde (sobre todo las mujeres) aprenden lenguajes, técnicas y actitudes que tienen que ver con la presentación de una misma y con la educación de los sentidos, el movimiento y la ocupación del espacio, la comunicación. Todo ello aderezado con dosis importantes de artificio. La parafernalia y la ritualización amorosa es todo lo contrario a la naturalidad. (Esteban 51)

El ritual de seducción entre Fiona y Jimmy pone en evidencia cómicamente los engranajes de la subordinación femenina en el erotismo. El primer acercamiento resulta una parodia de la relación paradigmática amorosa: el cortejo se muestra simplemente ridículo y artificial, carnavalesco, aunque no se distancia mucho de cualquier comedia romántica convencional.

\subsubsection{El encantamiento se desvanece}

La mascarada nocturna ha funcionado gracias a los disfraces y el escenario, pero en casa de Fiona Cenicienta se revela como tal. En el minuto 15'57», tras la secuencia de la discoteca y de una animada charla en el salón, Fiona y Jimmy se quedan a solas en la cocina. Él que se ha quedado sin camisa, empapado por las copas que derramó, se abalanza sobre ella y la besa. Ella se ríe y se aparta diciendo: «No puedo» y haciendo una seña con el brazo recuerda la presencia de los niños, es decir, su papel de madre, incompatible con la espontaneidad sexual. El momento de la negación forma parte fundamental del cortejo erótico normativo. La mujer primero atrae, «se ofrece» al varón (Bataille 136) mediante el aderezo y el gesto, pero debe resistirse en algún momento: «Ofrecerse es la actitud femenina fundamental, pero al primer movimiento -el ofrecimiento-, le sigue el fingimiento de su contrario» (Bataille 138). Él no cesa, pues esto forma parte del juego, e inmediatamente apaga una luz y en la penumbra crea el ambiente romántico adecuado para la entrega amorosa. Se acerca de nuevo a ella con una frase ingeniosa mientras ella ríe, pasando a un primer plano fijo de las cabezas de ambos de perfil. Mirándose entre sí y cada vez más próximos el uno al otro, se emborrona lo demás: el resto del mundo, la familia y los problemas desaparecen, sólo están los dos enamorados rodeados de oscuridad. Entonces Jimmy remata

Feminismo/s 32, diciembre 2018, pp. 313-341 
el ritual del cortejo declarándose en voz queda y susurrante mientras ella escucha fascinada:

¿Sabes? La primera vez que te vi bailando hace como un mes en el Crobar, estaba desesperado por invitarte a una copa. Normalmente soy tímido y me dije a mí mismo: No puedo, ella no querrá. No podrá ser... Entonces, esta noche te volví a ver. Todo parecía indicar que iba a lograr una segunda oportunidad para causarte una buena impresión.

El éxito de Jimmy requiere, una vez confirmada la atracción física de Fiona, explicitar que ha cumplido con las reglas de seducción romántica: el varón espera según un plan, toma la iniciativa: «invitar a una copa», y paga para demostrar poder y generosidad. Pero lo más importante es que la ha elegido a ella entre todas las demás, satisfaciendo el deseo monógamo romántico de ser deseada por encima de ninguna otra. De hecho, más tarde Fiona le exigirá por teléfono que justifique su elección, y él contestará satisfactoriamente: «eras distinta y mejor que todas las demás, porque no te preocupabas por gustar». Se pone de relieve la paradoja de la «naturalidad» femenina perfomatizada a través de adornos, gestos y movimientos que en el cortejo amoroso emplea para ofrecerse al deseo, pero negándolo, pues lo que diferencia a la mujer «decente» de la prostituta es que la prostituta se ofrece claramente sin fingir una negativa (Bataille 138). Esto se complementa con la alusión que hace Jimmy al mito de «la media naranja», de la persona adecuada que se justifica por el «flechazo», o atracción sexual, requisitos fundamentales en el amor romántico. Tras estas palabras, Fiona suspira y se escucha un desgarro de tela: el cuerpo femenino se ofrece a las caricias ya sin resistencia al confirmarse como único objeto de deseo. Ella se entrega y él, caballeroso, le susurra: «Dime que pare y pararé». Ambos se mantienen silenciosos mientras se besan primero despacio, pero ella de pronto se apasiona y él la frena: «Despacio, despacio, tómatelo con calma, más despacio».

Él ha incitado la situación y debe controlarla. Fiona ha olvidado por un momento su papel, Jimmy debe reconducir su deseo, su fogosidad, domarla. El varón debe mantener la calma según el orden patriarcal, pues la racionalidad es propia del hombre, y Fiona, como mujer, le hace descender hacia los instintos, porque ella es considerada «naturaleza» desde la racionalidad fundada en Grecia y reforzada a lo largo de la historia del pensamiento occidental. Racionalidad ésta, patriarcal, que establece y justifica la dominación

Feminismo/s 32, diciembre 2018, pp. 313-341 
masculina por la oposición binaria «cultura/ naturaleza», que se corresponde con la contraposición «hombre/mujer» (Amorós 31). Fiona así se rebela contra el rol femenino de castidad, rebelión por la que será fustigada durante toda la serie. Él, sin embargo, performativiza la idea de amor platónico que trasciende lo sexual, que a través de lo sensual alcanza el encuentro sublime de las almas. No obstante, vence Fiona recreando la caída bíblica masculina, y vuelven a besarse apasionadamente. Cada vez que él dice «más despacio», ella se acelera más, hasta que salen de plano, y en un encuadre general distante el encuentro sexual se desarrolla por toda la cocina en un baile desesperado en el que ella ahoga los gemidos mientras él le aparta el vestido ofreciendo al espectador su cuerpo desnudo. Se observa en ésta y todas las escenas de sexo cómo el cuerpo de Fiona es objeto de mirada privilegiado, fragmentado e íntegro, sobre el que el espectador puede ejercer libremente la mirada del voyeur.

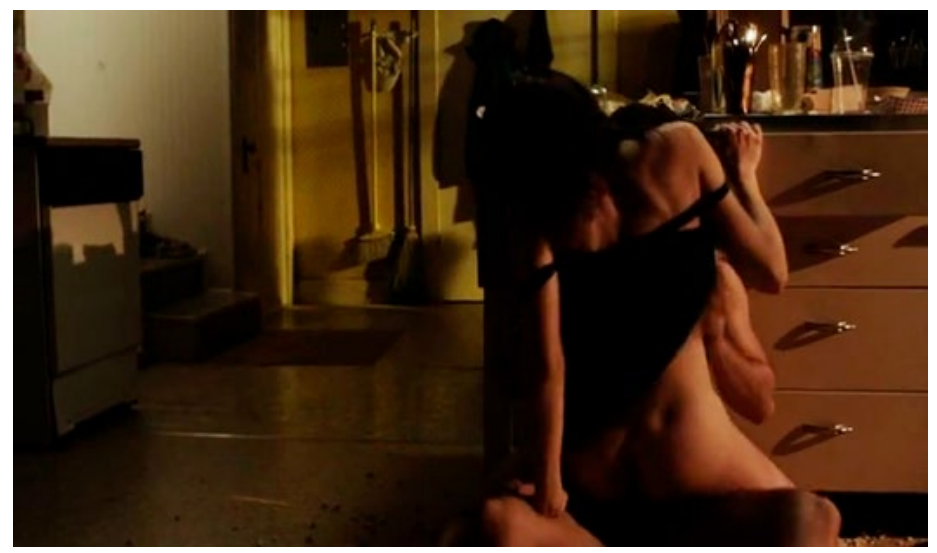

En medio del encuentro sexual, sonará el timbre y los amantes tendrán que separarse aparatosamente. La interrupción de la escena erótica la provocará un policía, pretendiente de Fiona, que trae y deposita en el suelo de la cocina a su padre, Frank (William H. Macy) borracho e inconsciente: metafórica y literalmente la carga de Fiona. Esto supondrá un quiebre en la magia nocturna. En esta secuencia se advierte la imposibilidad, no solo de la culminación del éxtasis sexual, que a lo largo de la relación se verá a menudo interrumpido por las exigencias de las tareas domésticas y de cuidados que

Feminismo/s 32, diciembre 2018, pp. 313-341 
recaen sobre Fiona, sino de la propia relación afectiva. Así se pone de relieve la realidad de Fiona-Cenicienta, y se anticipa la brecha, no sólo de género sino también de clase, entre los dos amantes.

Vemos sintetizada en estas dos secuencias la relación entre Jimmy y Fiona: una relación de roles estereotípicos basada fundamentalmente en la atracción física, impulsiva e irracional. También observamos los futuros conflictos de la pareja, que se repetirán en casi todas las relaciones de Fiona: «Es que todos intentan cambiarla, y no se da cuenta, y sigue uno tras otro, porque ella no quiere someterse, pero cuando crees que ya ese la quiere como es...otra vez» (mujer de 22 años, clase obrera).

\subsection{Lo grotesco cuando el príncipe pide consuelo a Cenicienta}

El periodo «mágico» y pasional de la seducción es muy pronto sustituido por los problemas cotidianos de la pareja real, cuando las exigencias materiales pasan a primer plano. El romanticismo se eclipsa cuando él ya no puede proporcionar lujos, sin su trabajo glamuroso solo puede ayudar a Fiona, que sigue pluriempleada en trabajos no cualificados, precarios y temporales, dedicándose a las tareas domésticas y de cuidados. Esto le arrebata su atractivo viril, como Fiona confiesa a Vero: «No es sexy que parezca una niñera».

En el quinto capítulo de la tercera temporada se pone de manifiesto la quiebra en el romance cuando Jimmy descubre que su padre es homosexual. Este hecho, sumado a la ruina económica de su progenitor y el consiguiente divorcio de sus padres, lleva a Jimmy a la desesperación.

Las relaciones sexuales se hacen imposibles, y su obsesión le lleva a lamentarse constantemente. De hecho, cuando va al bar de Kevin (Steve Howey), compañero de Vero, a emborracharse y quejarse, Kevin le advierte que su rol de «macho» está siendo puesto en cuestión con tanto lamento, y le recuerda que Fiona tiene problemas reales más importantes, «como llevar comida a casa».

En el minuto 39'57» de este capítulo, encontramos a la familia Gallagher al completo junto a unos borrachos a los que Frank ha persuadido de que hay oro enterrado en su jardín. Se hallan cavando y dinamitando en busca del cadáver de la tía de Frank, dueña de la casa en la que viven, y que él enterró para seguir viviendo allí y cobrar la pensión de la anciana. Ahora que se va a 
reformar la acometida del agua y van a levantar el jardín, temen ser descubiertos. Entonces Jimmy aparece ebrio, como un espectro, tambaleándose con el vaso de whisky aun en la mano, atravesando una nube de humo provocada por uno de los explosivos caseros que están usando para cavar.

Jimmy: Oye, de verdad, en cuanto a lo que ha pasado con mi padre...

Fiona: Oh Dios... ¿Por qué tenemos que seguir hablando de eso? ¿Todavía estás así? ¡Joder!

Jimmy: Muy bien, así que cuando tú me necesitas yo siempre estoy ahí, y por una sola vez que yo te necesito a ti ¿pasas de mí?

Él le recrimina no cumplir el principio amoroso de entrega total. Ella replica exponiendo sumariamente sus problemas materiales frente a los existenciales/ ideológicos de Jimmy:

Fiona: Carl cree que ha sobrevivido a un cáncer. Molly cree que es una chica con pene. A Debbie la aterrorizan en la piscina pública. Este jardín apesta como una cloaca. Tengo a tres capullos borrachos manejando herramientas eléctricas detrás de mí, y las zorras de mi trabajo me han encerrado hoy en el baño. ¡iAh!! y cierto... puede que estemos todos a punto de ir a prisión... ¿Y tú quieres hablar? Pues toma una pala, y habla de lo que te dé la gana mientras cavas. De que tu padre se la suele chupar a algún adolescente... pero cava mientras hablas.

Jimmy: ¿Sabes qué? Estoy más que harto de jugar contigo a «mis mierdas son más grandes que las tuyas». Mi existencia y mi mundo se han derrumbado, y es como si tú no te hubieras dado cuenta. Te recuerdo que tenemos una relación, y lo que me importa a mí, debería importarte a ti.

Lo que pone de manifiesto Jimmy al decir «tenemos una relación» es el incumplimiento del principio romántico de la prioridad y unidad de la pareja frente al mundo, en la que prevalece el sacrificio recíproco y desinteresado:

Una configuración emocional e identitaria, la romántica, que jerarquiza las distintas interacciones amorosas y donde, [...] el amor sexual o de pareja queda absolutamente encumbrado y entra en tensión con otros tipos de amores (como el maternofilial), lo que posibilita a su vez la consolidación de un determinado orden social, desigual. (Esteban 44)

Fiona se hace cargo de su familia y de toda persona desvalida que pasa por su casa, por lo que no puede entregarse a una relación de exclusividad romántica, aunque ella sí que la exige. Fiona espera del varón que la cuide, que cumpla su rol masculino, que sea fuerte, asertivo y auto-reprima lo

Feminismo/s 32, diciembre 2018, pp. 313-341 
emocional, pero Jimmy procede de otra esfera de valores y exige tal atención sentimental que Fiona, al compararla con su propia situación, se mofa y se indigna. La clase trabajadora tiene menos recursos comunicativos en el ámbito de lo romántico mientras que la clase media y media-alta poseen «mayores recursos para afrontar las contradicciones culturales entre las definiciones del amor que exigen continuidad y longevidad, por un lado, y aquellas que lo asocian con un vínculo intenso y placentero» (Illouz 151). El habitus de las clases más desfavorecidas promueve modelos más desiguales de género en los que el rol social y laboral del varón se vincula más a los valores tradicionalmente viriles como la fortaleza y la reserva emocional, apartándoles de los asignados a la esfera femenina, como el de la comunicación sentimental (Bourdieu 163).

Fiona: Míranos, estamos intentando desenterrar un cadáver. ¿Cómo puedes comparar nuestras situaciones? (Jimmy hace un gesto de protesta como para replicar, niega con la cabeza suspirando, y se da media vuelta para marcharse).

Fiona: (Gritando al punto del llanto, mientras él se marcha) Oh, muy bien, márchate, ya veo lo mierda que eres. (Se detiene a mirarla desde lejos) Eso, vete a llorarle al maricón de tu padre. (Jimmy se va)

La necesidad de apoyo y reconocimiento simbólico que exige Jimmy de su pareja no es compatible con las necesidades de Fiona: «La definición estándar de romance apela a la competencia cultural y el modo de vida propios de la clase media» (Illouz 370). La crisis identitaria de Jimmy es un privilegio de clase, y se revela como absurda y trivial ante la inestable realidad de Fiona: él puede permitirse deprimirse por la disolución de la figura paterna y la pérdida de una referencia masculina hetero-normativa y requiere el apoyo de su pareja para reconstruir su universo simbólico, el reconocimiento de ella supone el restablecimiento de su virilidad. La incomprensión se hace mayor al constatarse la homofobia de Jimmy, frente a la asunción de la homosexualidad como algo inocuo y natural por parte de los Gallagher. El hermano de Fiona es homosexual y su madre bisexual, lo cual nunca le resultó problemático.

Lo patético e irracional de esta secuencia surge por el choque ideológico de clase y el incumplimiento de los roles de género: Jimmy se siente abandonado de los cuidados femeninos, mientras que Fiona añora la fortaleza y

Feminismo/s 32, diciembre 2018, pp. 313-341 
entereza masculinas en una situación en la que ella y su familia se juegan la supervivencia y la libertad. Mientras él viene de emborracharse y compadecerse porque la figura paterna no responde al ideal de familia heterosexual hegemónica: «Su mundo se ha derrumbado», es decir, sufre un problema principalmente moral, mientras el mundo tanto sentimental como material de Fiona ha estado siempre arruinado, al borde de la tragedia en precario equilibrio. Lo grotesco supone poner al mismo nivel el descubrimiento de la homosexualidad del padre, que la angustia de deshacerse de un cadáver que podría suponer prisión para Frank y Fiona, y centros de acogida para sus hermanos. Para él, el sustento de su existencia era su estatus familiar, su mundo simbólico, mientras ella sobrevive en las ruinas de las urgencias materiales de la precariedad del suburbio, donde la moralidad no es un problema de primer orden, cuando se ha de sobrevivir, a menudo al margen o en contra de la ley, siempre más contundente y desfavorable para los colectivos marginales. La diferencia de sus conflictos, de su ideología, de su comprensión de la realidad, es abismal, insalvable: hablan diferentes idiomas. Fiona corre un riesgo físico, la quiebra de Jimmy es su identidad, ella tiene en peligro su vida, no el sentido de su existencia, que para ella es luchar contra un destino siempre aciago. Las tribulaciones de Jimmy son un privilegio de un varón blanco de clase media, libre de las servidumbres de las «pasiones bajas», de las necesidades materiales. La desgracia de Jimmy respondería para el espectador a lo cómico significativo de Baudelaire, producido por la «imitación» de la realidad, de algo concreto, que se genera ante la contemplación de la desgracia ajena, desde la superioridad: «[...] la risa está íntimamente ligada al accidente de una antigua caída, de una degradación física y moral»(Baudelaire 18). Por otra parte, las desventuras de Fiona resultan absurdas por exageradas, pero pueden explicarse en términos de lo trágico: su sino asignado por ser mujer y por ser hija de quien es, un sino trágico, fatal e inevitable. Esta «mezcla de dominios para nosotros separados», de elementos, de dimensiones cotidianas que al unirse provocan extrañeza, resultan extravagantes, y nos distancian, provocando la risa o el estremecimiento, desubicándonos (Kayser 221).

Feminismo/s 32, diciembre 2018, pp. 313-341 

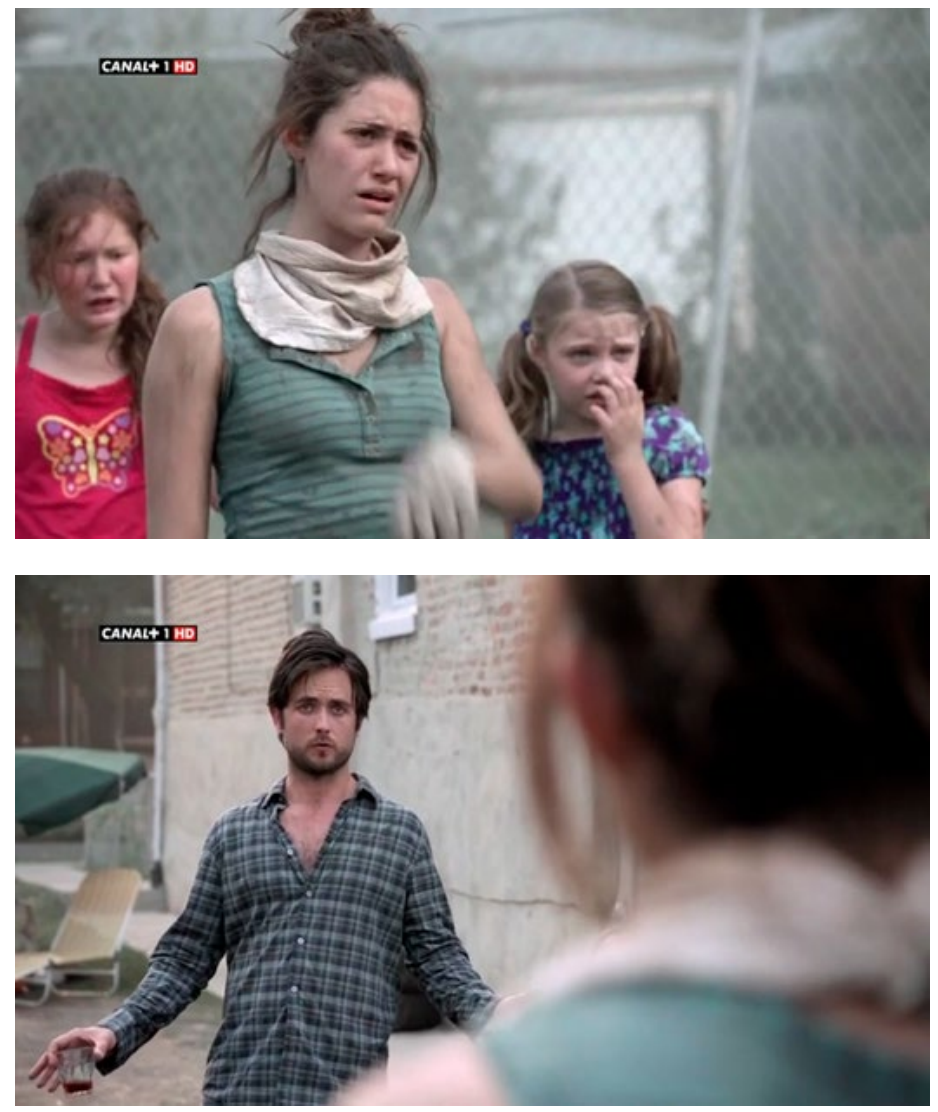

El amor romántico resulta aberrante en el marco de la miseria económica, según todas las personas entrevistadas. El amor debería salvar de toda calamidad, de trivializar las necesidades, de destrozar todas las barreras como las de clase y las de género, pero aquí se expresa sin piedad la distancia social y moral de los personajes: el amor romántico para una mujer del suburbio es ridículo. Este conflicto muestra la doble situación de opresión de Fiona: de género y clase, el abismo insalvable entre dos mundos al enfrentarse a las realidades cotidianas provoca la risa incómoda grotesca. El amor romántico se revela como absurdo bajo la mirada grotesca, como un privilegio para quienes

Feminismo/s 32, diciembre 2018, pp. 313-341 
están libres de las necesidades básicas. Por tanto, aquella mujer encargada de los cuidados y acuciada por la urgencia de las necesidades materiales, la mujer que debe luchar por su supervivencia y la de quienes tiene a su cargo, no puede desempeñar el rol de amante.

\subsection{Cenicienta cambia de cuento}

Pese a su fracaso con Jimmy, Fiona sigue buscando el amor, así que establece varias relaciones sucesivas, alternando hombres que aparentemente le ofrecen estabilidad con otros que claramente la destruyen. Fracasa estrepitosamente porque el ideal nunca se cumple, porque o ella es infiel o ellos no cumplen las exigencias que ella requiere, y se tambalea entre los estereotipos de santa y puta sin encarnar ni sentirse a gusto en ninguno. Así reincide en un bucle de fracasos sentimentales, que de una forma u otra repiten el esquema de la relación con Jimmy, bajo una mirada grotesca que desenmascara las mentiras y los engaños, así como los deseos contradictorios que intentan conjugar el relato romántico con el relato familiar y con el sueño norteamericano del ascenso social. En el último capítulo de la quinta temporada la plantan en el altar, así que en la siguiente temporada renuncia a las relaciones sentimentales, y justificándolo como una forma de empoderamiento, optará por relacionarse por Tinder limitándose al sexo ocasional para centrarse en su carrera profesional.

Cenicienta finalmente renuncia a los príncipes, no tiene tiempo para bailar todas las noches: el amor romántico resulta imposible entre los harapos del lumpen. Sin las pompas de la clase media burguesa, en la desnudez andrajosa del suburbio, lo desigual e injusto de los roles de género, o de la diferencia de clase, el peligro que planea constantemente sobre los parias, hace que el ideal de amor hegemónico aparezca como un engendro imposible para las clases más desfavorecidas.

\section{CONCLUSIONES}

La parodia en Shameless dinamita certezas; sin llegar a ofrecer una perspectiva feminista, pone en entredicho categorías que el ideario hegemónico se esfuerza en normalizar, y que son totalmente aceptadas hasta el punto de no poder concebirse de otra manera. Echa por tierra, mediante la mezcla

Feminismo/s 32, diciembre 2018, pp. 313-341 
heterogénea de elementos y una perspectiva diferente a la normativa, las ideas que rigen nuestro firmamento teórico amoroso, basado fundamentalmente en dicotomías esencialistas, de opuestos cerrados como el de masculino/ femenino, rico/pobre, madre/amante.

Los personajes no pueden cumplir el ideal burgués romántico, y ante la única posibilidad de acceso a la esfera de la fantasía amorosa mediante el simulacro, la relación se desvela como la mueca carnavalesca que pone en evidencia dicha imposibilidad. El relato sexo-afectivo de Fiona, personaje con el que se identifican todas las espectadoras de la serie entrevistadas, intenta representar una realidad social del suburbio, donde los dispositivos de seducción fracasan, los dispositivos de pareja defraudan, las relaciones amorosas demuestran que el amor burgués no tiene lugar entre los parias.

La mascarada desenmascara las convenciones, la parodia niega los originales normativos, los ideales estereotípicos de género que rigen nuestros actos no se pueden interiorizar del todo: «las normas de género a fin de cuentas son fantasmáticas, imposibles de encarnar» (Butler, El género en disputa 172). Así, la mirada enajenada sobre lo cotidiano muestra el absurdo de ciertos valores e ideales en torno a las relaciones sexo- afectivas.

Para las informantes mujeres, el fracaso romántico se debe o a que busca a los hombres equivocados o a que en su idea de amor adopta un rol que no la hace feliz. Pero los varones entrevistados no conciben el amor romántico como problemático, de hecho, perciben que Fiona no busca ese tipo de relación. Un informante de 33 años de clase obrera: «Sus relaciones son muy impulsivas y superficiales, no veo amor, veo más interés». Porque todos se refieren únicamente a una forma de relación amorosa auténtica, como otro entrevistado, de clase media y de 24 años, exclama: " $i$ Acaso existe otra forma de amor?». Según todos los entrevistados varones, independientemente de su estrato social o edad, Fiona fracasa precisamente porque no busca amor, sino sexo o conveniencia. Los varones entrevistados aceptan acríticamente y suscriben el concepto de amor romántico como concepto válido de amor, y achacan el fracaso a la mujer. Por el contrario, casi todas las mujeres entrevistadas, excepto una de clase media, son críticas, y señalan la desigualdad que se establece en la relación romántica: 
«Yo me identifico con Fiona sobre todo cuando la caga, cuando se lía con uno y sabes que el otro te trata tan bien..., pero te lías con ese que ha sido un cabrón, pero te mola... pero también cuando veo la dificultad de ser madre, o tener a tu cargo un crío e intentar conciliar tus relaciones con eso. La gente se asusta... Uhhh una madre, entonces aprendes a tomarte a los tíos de otra forma, con más distancia, a pensar incluso en relaciones abiertas» (mujer de 35 años, clase obrera).

Como observamos, el discurso del texto audiovisual muestra imposible conciliar el amor hegemónico o romántico con la vida laboral y la maternidad: «la capacidad de vivir el amor en un sentido auténtico se reserva sólo para aquéllos cuyas vidas no están determinadas por la necesidad» (Illouz 382). Por tanto, lo grotesco opera aquí como dispositivo crítico del amor romántico, mostrando la incompatibilidad de conjugar el rol de amante con los de madre y trabajadora precaria, pero sólo lo perciben así quienes se identifican con esta situación de subordinación de género y clase.

\section{REFERENCIAS BIBLIOGRÁFICAS}

Amorós, Celia. Hacia una crítica de la razón patriarcal. Barcelona: Anthropos, 1985.

Bajtin, Mijail. La cultura popular en la Edad Media y en el Renacimiento. Buenos Aires: Alianza, 1987.

Bataille Georges. El erotismo. Barcelona: Tusquets, 2007.

Baudelaire, Charles. Lo cómico y la caricatura. Madrid: Visor, 1988.

Bourdieu, Pierre. La dominación masculina. Madrid: Anagrama, 2000.

Butler, Judith. El género en disputa: el feminismo y la subversión de la identidad. Barcelona: Paidós Ibérica, 1999.

Connelly, Frances S. Lo grotesco en el arte y la cultura occidentales. Madrid: La Balsa de la Medusa. 2015

Dolan, Jill. The Feminist Spectator in Action: Feminist Criticism for the Stage and the Screen. New York, NY: Palgrave Macmillan, 2013.

Esteban, M. ${ }^{a}$ Luz. Crítica del pensamiento amoroso. Barcelona: Bellaterra, 2011. Illouz, Eva. El consumo de la utopía romántica. Madrid: Katz, 2009.

Kayser, Wolfgang. Lo grotesco en pintura y literatura. Buenos Aires: Nova, 2010. Morley, David. Televisión, audiencias y estudios culturales. Buenos Aires: Amorrortu editores, 1996.

Feminismo/s 32, diciembre 2018, pp. 313-341 
Mulvey, Laura. «Placer visual y cine narrativo». Arte después de la Modernidad: nuevos planteamientos en torno a la representación. Ed. B. Wallis. Madrid: AKAL, 2002.

Rochlin, Margy. «The family that frays together». The New York Times 2 enero 2011: AR7.

Rojas Soriano, Ramón. Guía para realizar investigaciones sociales. México: Plaza y Valdés, 2001. 